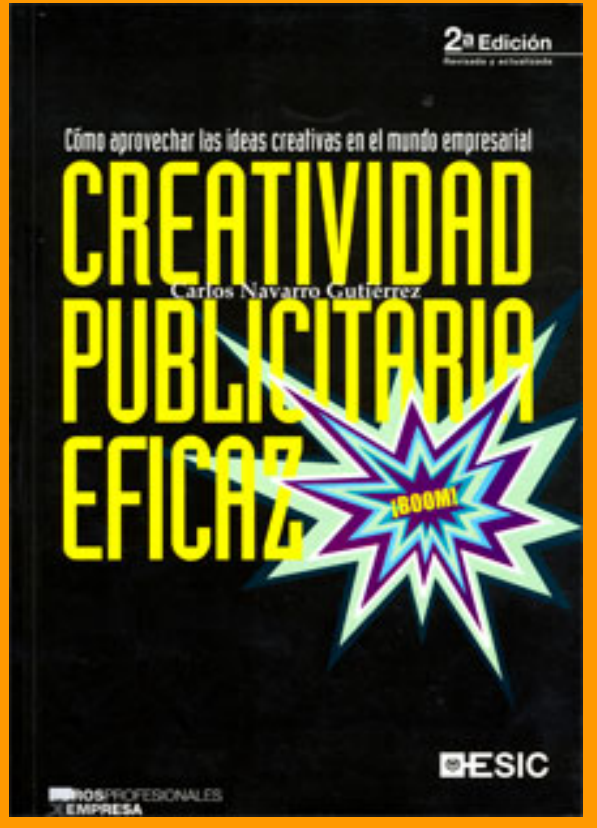

CREATIVI DAD PUBLI CITARIA

EFICAZ

Carlos Navarro Gutiérrez

Madrid,ESIC Editorial, 2007

309 páginas

\title{
Reseña por
}

J avier Lozano Delmar

Como el propio subtítulo del libro deja entrever, Cómo aprovechar las ideas creativas en el mundo empresarial, el objetivo del libro Creatividad publicitaria eficaz no es otro que enseñarnos a ser creativos y, a partir de esto, realizar buenos anuncios. El autor es todo un especialista en el tema, Carlos Navarro, que comenzó como creativo publicitario en la empresa Young \& Rubicam en 1974 y que, en la actualidad, posee su propia consultora creativa, además de ser profesor asociado de Publicidad en la Facultad de Ciencias de la Información de Madrid, y de enseñar Creatividad en la carrera de Publicidad y RR.PP. de ESIC.

Desde las primeras páginas, el libro deja claro que la cualidad de la creatividad es algo que está ahí, presente, y que todos podemos acceder a ella. Todos podemos utilizarla para crear anuncios originales y eficaces. "Las posibilidades de pensar el mundo de otra manera no son exclusivas de nadie" (p. 22). Carlos Navarro explica, poco a poco, cómo desarrollar estas técnicas creativas a la vez que va haciendo todo un repaso por el panorama de la profesión publicitaria. De esta forma, se detallarán casi todos los procesos a la hora de realizar una campaña publicitaria. Se hablará tanto del cliente como del consumidor y, en la mayor parte de los casos, y dada su experiencia en el tema, el autor ofrecerá toda una serie de ejemplos o plantillas de algunas campañas. Así, podremos ver modelos de Briefings online o de E.S.E. (Esquema de Selección Estratégica), de tal manera que, para el lector inicial, la lectura sirva de aprendizaje y de primer contacto con el medio.

El libro está dotado de un tono optimista y positivo. Todo el mundo puede ser creativo. El autor anima a que se practiquen las artes de la creatividad. Durante el desarrollo de la obra 
se incluirán, incluso, algunos ejercicios (a modo de "deberes escolares") para que el lector que lo desee compruebe hasta donde puede llegar experimentando con su propio cerebro. Se trata de un libro activo en el que el lector no va a aburrirse. Así, utilizando un tono personal y amistoso, el autor se permitirá confesar, en cada uno de sus capítulos, algunas experiencias propias relacionadas con el tema (apartados que titulará muy acertadamente "La creatividad tal como es"). Además de esto, al final de cada capítulo, se incluirá otro apartado titulado "En pocas palabras" en el que, a modo de esquema, se resumen, en una serie de líneas, los aspectos tratados más importantes. De esta forma, Creatividad publicitaria eficaz se constituye como un estudio del panorama publicitario actual, además de como un perfecto manual de referencia para el estudiante o el lector más primerizo en el tema.

Conforme vamos avanzando en la lectura del libro, compuesto de nueve capítulos, se nos van desvelando los diferentes entresijos de la creatividad publicitaria. El autor parte desde el primer capítulo ("¿Y valgo yo para creativo?") de la premisa de que nadie debe abandonar y rendirse a la hora de enfrentarse a la creatividad. No debemos deprimirnos y pensar que no servimos sino descubrir para qué servimos: "La pregunta correcta que nos deberíamos hacer no es ¿soy creativo? Sino ¿en qué soy creativo?" (p. 23). Tras esto, el autor promete ir desvelando, poco a poco, diferentes estrategias para descubrir nuestra propia creatividad.

El segundo capítulo, "Anuncios que enamoren", habla de la marca, de cómo la principal función de ésta es ser recordada por el público. "La meta de la creatividad es situar marcas en la memoria de quienes las puedan necesitar" (p. 41). Se comenta cómo la publicidad emocional es una de las mejores técnicas a la hora de definir un producto y, cómo los estereotipos ayudan a esto. En los siguientes capítulos ("La creatividad empieza por el cliente", "Creatividad visual y verbal: dirección de arte y copy" y "Cómo acabar creativamente con el enemigo") se recogen y estudian casi todos los integrantes y procesos que conforman la realización de una campaña publicitaria. Así, se explica lo que es un briefing y se definen los conceptos de ventajas competitivas y ventajas higiénicas. Se profundiza en las profesiones del Director de arte y del Copy (explicando las labores que desempeñan) y se detalla qué son y cómo funcionan las estrategias creativas y sus diferentes partes.

El capítulo sexto ("La marca se hace persona") trata nuevamente el concepto de la marca, pero, esta vez, de una forma mucho más práctica. Así, se dan consejos sobre cómo buscar un buen nombre de marca y se define el concepto de logotipo, como resumen visual de ésta. Se explican conceptos como el de la publicidad interactiva, tan habitual hoy en día, y el de la "personificación de las marcas".

"Cómo dar a luz las ideas" se centra en la idea creativa, la idea del anuncio. Y, ¿Cómo podemos encontrar esa idea creativa? El autor explica que esto no es un proceso inmediato sino que, más bien, se trata de un proceso que tendrá en cuenta todas las etapas vistas anteriormente, partiendo del briefing y pasando por las estrategias creativas. Se recogen, 
además, varias técnicas inventadas y utilizadas para el acto de generar ideas: desde la técnica de las cinco etapas de J.W. Young a la técnica de los seis sombreros. El autor comenta también la importancia de desarrollar la idea en un formato narrativo adecuado y de la tarea efectuada por los producers, aquellas personas encargadas de encontrar el camino técnico más conveniente para resaltar los valores de la marca. Sin embargo, si bien este primer análisis sobre las tareas de producción resulta un poco breve, en el siguiente capítulo ("Las ideas se echan a la calle") se concederán unas líneas más a tratar el tema. De este modo, conoceremos, entre otras cosas, como se constituyen y para qué sirven las PPM (Pre-Production Meeting).

El último capítulo ("Creativos a la velocidad de la luz") se centrará en el estudio de los nuevos soportes electrónicos. Existen nuevas conductas frente al consumo que exigen nuevas formas de creatividad. De esta forma, el autor trata el tema de la publicidad en internet y da consejos sobre cómo obtener mayor rendimiento a un sitio web. Se concluirá el capitulo comentando el concepto de advergaming, o publicidad dentro del videojuego. Carlos Navarro explicará y desarrollará los tipos de publicidad que existen dentro de este nuevo ámbito que está surgiendo y se planteará porqué no existen más anuncios sobre videojuegos dado el creciente consumo que hay de éstos.

Creatividad publicitaria eficaz concluye con cuatro anexos. El primer anexo (titulado "Palabras para entender la creatividad") es un útil diccionario de términos publicitarios. El segundo anexo lo constituye un extenso listado de websites que comprende desde páginas de interés publicitario y creativo hasta páginas que nada tienen que ver con la publicidad: sitios de becas de estudios, de descargas de programas de ordenador... Asimismo, el autor distingue entre lo que él denomina "Documentos de interés" (tercer anexo), que vendrían a ser aquéllos mejor relacionados con el estudio que ocupa, y la "Bibliografía" estándar (cuarto anexo), donde se incluyen toda una serie de libros y manuales que versan sobre el tema publicitario en general.

En resumen, nos encontramos ante un libro interesante y ameno, escrito por alguien veterano en el oficio. Un creativo que, a lo largo de la obra, se plantea porqué la creatividad a día de hoy carece de valor económico. ¿Cuánto cuesta la creatividad?, ¿Qué precio tiene todo ese trabajo realizado por los creativos? Nos encontramos ante una profesión sufrida, en la que la generación de ideas es el punto de partida para la realización de una campaña que, ante todo, debe, ya de por sí, intentar ser la más original y creativa que exista. Se trata de competir constantemente y, a la vez, de llegar al consumidor, hacerle recordar su marca específica en detrimento de las demás: "La creatividad tiene que ayudar a las ventas de la marca" (p. 30). No es una tarea fácil como podemos ver. Y, si esto es así, ¿por qué no se reconoce ese valor a la hora de la factura?. Según señala Carlos Navarro, es raro el presupuesto en el que se incluye específicamente el precio de esta tarea. Por ello, hace una especie de llamamiento a aquellos profesionales creativos para que este oficio adquiera valor y no acabe siendo absorbido como una tarea más de la agencia de publicidad. 
Con este libro, Carlos Navarro nos hace comprender y, lo que es su mayor logro, amar el arte de la creatividad. Aunque nuestras cualidades sean nulas a este respecto o aunque no se tenga ningún conocimiento acerca de cómo llevar a cabo una campaña publicitaria, el libro nos aporta en todo momento algo de esperanza y confianza. Así, Creatividad publicitaria eficaz se constituye como un perfecto y "eficaz" manual para comprender la ardua tarea de la creatividad en general, y de la publicitaria en particular. 